\title{
Grooming behavior and gene expression of the Indiana "mite-biter" honey bee stock
}

\author{
Nuria Morfin ${ }^{1}$, Krispn Given ${ }^{2}$, Mathew Evans ${ }^{3}$, Ernesto Guzman-NovoA ${ }^{1}$, \\ Greg J. HunT ${ }^{2}$ \\ ${ }^{1}$ School of Environmental Sciences, University of Guelph, 50 Stone Road East, Guelph, Ontario N1G 2W1, Canada \\ ${ }^{2}$ Department of Entomology, Purdue University, 901 W State St, West Lafayette, IN 47907, USA \\ ${ }^{3}$ Woodland Honey, Van Buren, IN, USA
}

Received 28 March 2019 - Revised 9 August 2019 - Accepted 24 October 2019

\begin{abstract}
This study was conducted to evaluate the Indiana "mite-biter" honey bee stock, which has been selected for increased mutilation of Varroa destructor mites ("mite biting" behavior). A comparison between colonies of the selected stock and colonies of unselected Italian bees showed that the proportion of mutilated mites, the severity of mutilations, and winter colony survival were higher in Indiana mite-biter colonies. Additionally, the number of fallen mites and the rate of mite population growth were lower in the colonies of the selected genotype than in those of the unselected genotype. The expression of a gene associated with grooming behavior, AmNrx-1 (neurexin), was significantly higher in the selected stock. Moreover, AmNrx-1 expression was positively correlated with the proportion of mutilated mites but not with mite population growth. AmNrx-1 may have the potential to be used for marker-assisted selection. This study provides evidence that selection for mite-biting behavior reduces $V$. destructor infestations, increases colony survival and increases the expression of a grooming behaviorassociated gene.
\end{abstract}

Varroa destructor / grooming behavior / chewed mites / gene expression

\section{INTRODUCTION}

Studies conducted in Europe and North America have demonstrated that the single most important factor associated with honey bee colony mortality is the mite Varroa destructor (GuzmanNovoa et al. 2010; Le Conte et al. 2010). Relatively low mite infestation levels can cause severe damages in bees of different genotypes (De Jong 1997; Bowen-Walker and Gunn 2001; Büchler

Electronic supplementary material The online version of this article (https://doi.org/10.1007/s13592-019-00710-y) contains supplementary material, which is available to authorized users.

Corresponding author: N. Morfin, nmorfinr@uoguelph.ca

Manuscript editor: Klaus Hartfelder et al. 2014; Reyes-Quintana et al. 2019). Two bee behavioral traits that restrain $V$. destructor population growth in colonies are grooming behavior (Rinderer et al. 2010; ArechavaletaVelasco and Guzmán-Novoa 2001), the removal of mites from the bees' bodies, and the Varroa sensitive hygiene (VSH) trait, which involves the ability of bees to detect and remove infested brood where $V$. destructor reproduces (Ibrahim and Spivak 2006; Harbo and Harris 2009). Stocks selected for increased VSH by researchers from the United States Department of Agriculture (USDA) have been made available to North American queen breeders (Danka et al. 2011).

Grooming behavior, however, is difficult to measure because there are no practical assays to test colonies and thus, honey bee stocks selected for this trait are not generally available to queen 
producers. Nevertheless, individual grooming assays have demonstrated that vigorous grooming is important for successful removal of mites from bees (Guzman-Novoa et al. 2012), although intense grooming could decrease by $V$. destructor parasitism (Morfin et al. 2019). Individual assays were also used in backcrossed bees that were genotyped at over 1000 single nucleotide polymorphisms (SNPs) to identify quantitative trait loci (QTL) associated with this behavior (Arechavaleta-Velasco et al. 2012). The most significant QTL region in chromosome 5 contained $A m N r x-1$, a gene that encodes for neurexin-1, a presynaptic protein involved in synapse differentiation and function (Tabuchi and Südhof 2002). Individual bees that were vigorous groomers exhibited higher expression of AmNrx-1 compared to bees that groomed lightly or not at all (Hamiduzzaman et al. 2017). In other species, this gene has been associated with neural disorders such as autism in humans (Kim et al. 2008) and auto-grooming in mice (Etherton et al. 2009).

One study reported that the proportion of damaged mites (presumably chewed by worker bees) that fall onto sampling sheets is a good indicator of grooming behavior (Andino and Hunt 2011). This colony trait, referred to as "mite biting," has been used in a breeding program to select for increased $V$. destructor resistance (Hunt et al. 2016). The program is currently carried out by Purdue University's researchers in collaboration with beekeepers from USA Midwest states. In a previous study, the selected stock was compared to commercial Carniolan stocks by beekeepers in the Midwest region. "Mite-biter" colonies had about one-third of the mite levels and higher annual survival rate than Carniolan commercial bees (Hunt et al. 2016). Additionally, other honey bee stocks selected for low mite population growth have shown significantly lower numbers of fallen mites and higher percentages of injured mites compared to unselected stocks (Guzman-Novoa et al. 2012).

The aim of this study was to assess the efficacy of selecting for increased mutilation of $V$. destructor mites as a tool to breed $V$. destructor resistant bees and the possible involvement of AmNrx-1 in mite biting behavior. We expanded the evaluation of the Indiana mite- biter stock by comparing it with an Italian commercial genotype for $V$. destructor mutilations, mite population growth, and winter survival. We also correlated mite population growth and the proportion of mutilated mites with the expression of AmNrx-1 in bees, to assess the value of this gene as a potential marker of $V$. destructor resistance.

\section{MATERIALS AND METHODS}

\subsection{Colonies}

An apiary with 36 colonies was established in West Lafayette, IN, USA. Half of the colonies were headed by sister queens from the stock selected for increased mutilation of $V$. destructor mites, or Indiana mite-biter, and half were headed by sister queens from unselected Italian bees. The Indiana mite-biter queens were reared from the selected stock established in 1997 at Purdue University, which initially included a queen from VSH stock and two Russian queens, but the majority of the initial population was from local Indiana queen breeders and feral colonies collected in Indiana and Ohio. The Italian queens used in this study came from a commercial California breeder that did not attempt to select for grooming behavior. The experimental colonies were created by dividing the bee population and brood of colonies into two equal parts. The divisions of the colonies were made on early June 2017. The resulting colonies contained three frames of brood and a frame of honey and pollen, plus the adhering bees to provide a starting population of about 15,000 bees. Since the divided colonies were to remain in the same apiary, emerging brood and combs with nurse bees were preferentially placed in the colony that was to be at a new hive location within the apiary and the colonies were turned around to face the perimeter of the apiary. These measures were taken to minimize drifting and to obtain equal colony populations since most older field bees attempt to return to the original location. A test queen of each type was introduced into each half of each divided colony. The allocation of the queen types to the experimental colonies was done at random. The population of the colonies (number of frames with brood and adult bees) was 
evaluated as per Delaplane et al. (2013) and was similar between the colonies included in the experiment. All the colonies received the same management throughout the course of the experiment and were not treated for $V$. destructor control.

\section{2. $V$. destructor infestation levels, biting behavior, and winter survival}

$V$. destructor infestation levels and the proportion of damaged ("chewed") mites were determined twice in each colony in July and October 2017. The initial evaluation of the colonies began 24 days after the introduction of queens to the experimental colonies. At this date, the first worker daughters of these queens would have been emerging as adults for just a few days. Three of the Italian colonies dwindled in population and died in September, prior to the fall sampling and were excluded from the analyses. These colonies were highly infested with mites and had bees with deformed wings and signs of brood diseases such as chalk brood and European foulbrood that looked typical of parasitic mite syndrome. $V$. destructor infestation levels were determined by mite fall onto paper sheets that were lightly covered with vegetable oil and placed underneath screen bottom boards in each hive. To determine the increase in mite population in each colony during 16 weeks, the mite fall count of July was subtracted from the mite fall count of October as per Emsen et al. (2012). The mites that fell onto the sheets during three days were counted and examined under a stereoscopic microscope $(\times$ 15 ) for missing appendages or mutilated idiosoma. Additionally, the relative severity of the mutilations for each colony was ranked from one to four, based on the average number of bites (missing or partial legs and/or mutilated idiosoma). Lastly, the colonies used in the study were left to overwinter, and the number of colonies that survived was recorded in February 2018. At this time, the experiment was concluded and the beekeeper that donated the bees removed the hives. Previous experiences have shown us that when keeping resistant and susceptible stock in the same apiary, mites from collapsing colonies will infest the survivors and cause them to eventually collapse as well (unpublished data).

\subsection{RNA extraction, cDNA synthesis, and relative gene expression (qRT-PCR)}

Total RNA was extracted from a pool of 30 honey bee heads per colony, from the 33 colonies (15 Italian and 18 Indiana mite-biter colonies) using TRIzol@ reagent (Invitrogen, Carslbad, CA, USA) as per manufacturer's protocol. cDNA for qRT-PCR reactions was prepared using 2000 ng of RNA for each sample (RevertAid ${ }^{\text {TM }}$ $\mathrm{H}$ Minus First Strand cDNA Synthesis Kit; Fermentas, Burlington ON, Canada). The qRTPCR was performed with a BioRad CFX96 ${ }^{\text {TM }}$ thermocycler (Bio-Rad Laboratories, Mississauga, ON, Canada) with PowerUp ${ }^{\text {TMSYBR }}{ }^{\mathrm{TM}}$ Green Master Mix (Applied Biosystems, CA, USA). The efficiencies of the target and reference genes were determined based on the standard curves of known concentration of $300 \mathrm{bp}$ synthetic gene fragments (Integrated DNA Technologies, IA, USA). The PCR reactions were done in a final volume of $20 \mu \mathrm{l}$ with primer concentrations per reaction of $200 \mathrm{nM}$ for the reference gene, $A m G A P D 2$, and $400 \mathrm{nM}$ for the target gene, AmNrx-1. The cycling protocol consisted of one cycle at $50{ }^{\circ} \mathrm{C}$ for $2 \mathrm{~min}$, one at $95^{\circ} \mathrm{C}$ for $10 \mathrm{~min}$, and then 40 cycles at $95^{\circ} \mathrm{C}$ for $15 \mathrm{~s}$ and $60^{\circ} \mathrm{C}$ for $60 \mathrm{~s} . A m G A P D 2$ was amplified with the primers used by Thompson et al. (2007), and AmNrx-1 was amplified using the primers $5^{\prime}$ CTGCTTCGAGCGACGACTAT and 5' ACGACCGGATGGATGATTGG, designed for this study using Primer-BLAST (National Centre for Biotechnology Information, US National Library of Medicine), which amplified a PCR product of 212 bp (positions 3554-3765; GenBank accession no. FJ580046.1). The $2^{-\Delta \Delta}$ (Livak) method (Livak and Schmittgen 2001) was used to calculate $A m N r x-1$ relative expression and fold difference for Italian and Indiana mite-biter bees.

\subsection{Statistical analyses}

The data on the proportion of chewed mites were subjected to Shapiro-Wilk tests and arcsinesquare root transformed because they did not comply with the assumption of normality. Then, the data from both genotypes were compared with a Student $t$ test $(\alpha=0.05)$. To compare genotypes 
for mite fall as well as for $V$. destructor population growth (number of mites fallen in October minus number of mites fallen in July), the data were subjected to Wilcoxon signed-rank test ( $\alpha=$ 0.05 ) as it did not follow a normal distribution. A Wilcoxon signed-rank test ( $\alpha$ of 0.05 ) was also used to compare the genotypes for severity of mite mutilation. The AmNrx-1 expression data were subjected to a Shapiro-Wilk test, and subsequently, square-root transformed because they were not normally distributed. Then the data from both genotypes were compared with a Student $t$ test $(\alpha=0.05)$. In addition, tests for differences in AmNrx-1 expression between the 15 Italian colonies and between the 18 Indiana mite-biter colonies were performed using one-way ANOVAs and Fisher LSD tests ( $\alpha$ of 0.05 ). Spearman rank correlation analyses ( $\alpha$ of 0.05 ) were conducted to determine relationships between the proportion of mutilated mites and AmNrx-1 expression, and between mite population growth and AmNrx-1 expression. All statistical analyses were performed using R, version 3.4.3@ (The R Foundation for Statistical Computing 2014).

\section{RESULTS}

The overall proportion of mutilated mites from the Indiana mite-biter colonies was significantly higher than that from the Italian colonies $\left(t_{(31)}=\right.$ $-4.34, p<0.0001$; Figure 1) and there were no differences in the proportion of mutilated mites collected from colonies of both genotypes between the sampling dates $\left(t_{(34)}=0, p=1.0\right.$, $t_{(29)}=-0.20, p=0.84$, respectively). Additionally, the scores for severity of mite mutilation were significantly higher for the Indiana mite-biter colonies than for the Italian bee colonies $(Z=-4.14$, $p<0.0001$; Figure 2).

$V$. destructor populations grew significantly more in the Italian bee colonies $(310.66 \pm 42.23)$ than in the Indiana mite-biter colonies (106.88 \pm 15.75) $(Z=-3.23, p=0.001$; Figure 3$)$. These results corresponded to a nearly 3 -fold higher number of fallen mites in October in the Italian bee colonies compared with the mite-biter colonies.

AmNrx-1 expression was significantly higher in bees from mite-biter colonies (1.2-fold) than in

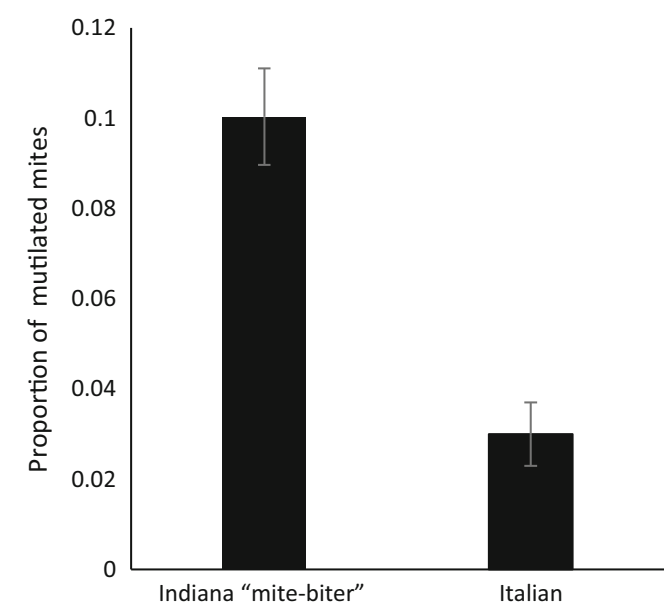

Figure 1. Mean proportion of mutilated $V$. destructor mites ( \pm S.E.) from honey bee colonies headed by Indiana "mite-biter" and Italian queens $(N=33)$. Significant differences ( $p<0.05$, Student $t$ test) between Indiana "mite-biter" and Italian bee colonies were found.

bees from Italian bee colonies $(t=-3.77$; $p<0.0001$; Figure 4). However, there were sig-

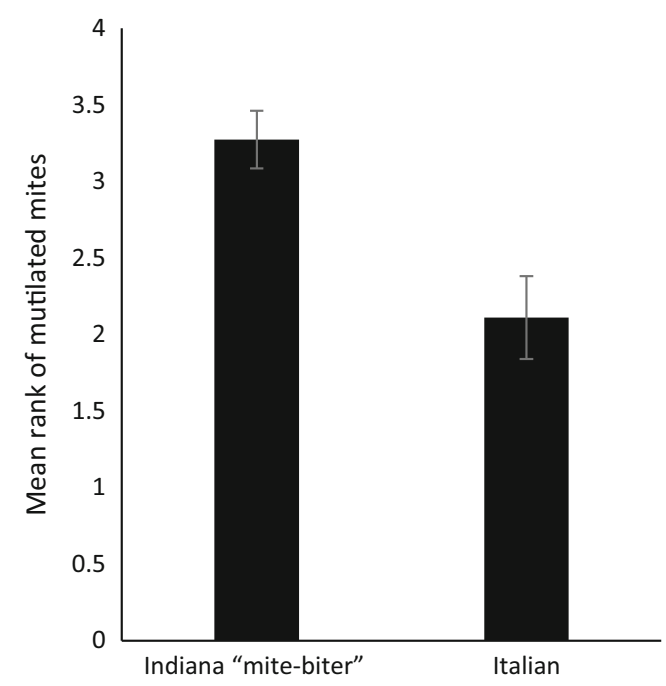

Figure 2. Mean ranks of severity of $V$. destructor mutilation ( \pm S.E.) from Indiana "mite-biter" and Italian bee colonies $(N=31)$. The relative severity of the mutilations was ranked from one to four, based on the average number of bites. The ranked data was subjected to a Wilcoxon signed-rank test. Significant differences $(p<0.05)$ between Indiana "mite-biter" and Italian bee colonies were found. 


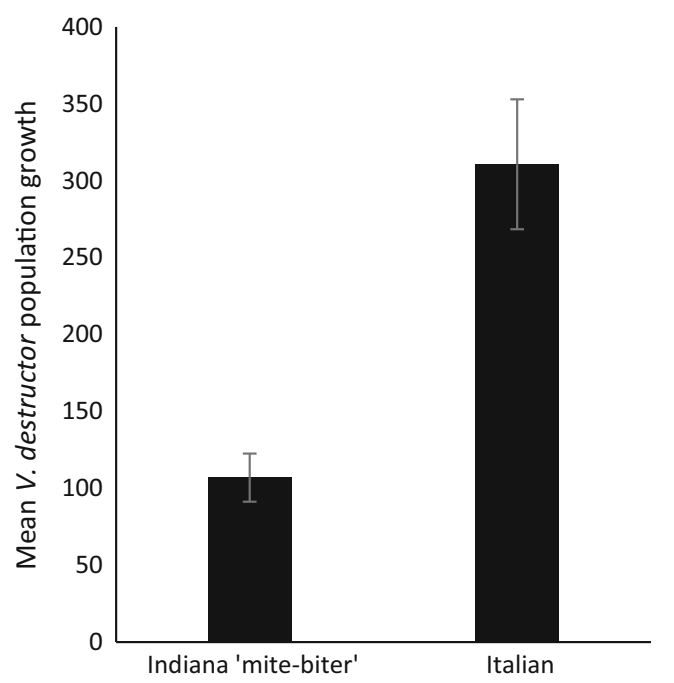

Figure 3. Mean $V$. destructor population growth (number of mites fallen in October minus number of mites fallen in July) ( \pm S.E.) from honey bee colonies headed by Indiana "mite-biter" and Italian queens $(N=33)$. Significant differences $(p<0.05$, Wilcoxon signedrank test) between Indiana "mite-biter" and Italian bee colonies were found. Non-transformed data is presented.

nificant differences in the level of expression of this gene between bees of different Italian

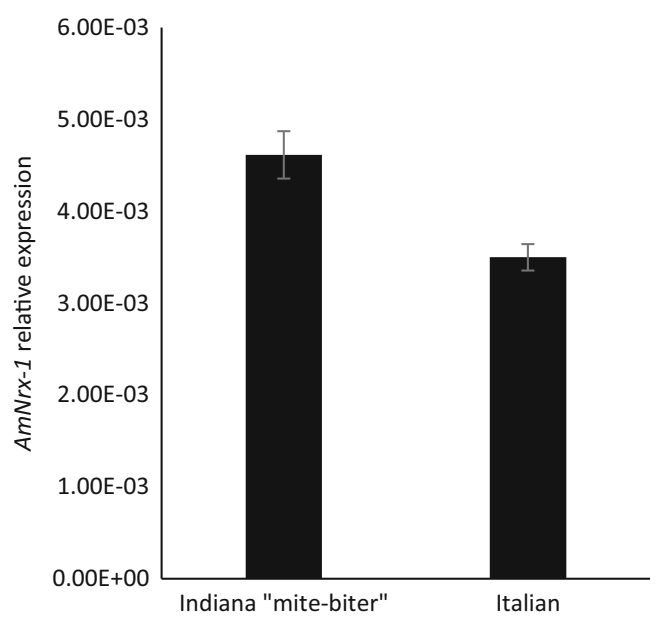

Figure 4. Expression of $A m N r x-1$ relative to the reference gene AmGAPD2 ( \pm S.E.) from a pool of 30 bee heads from 18 Indiana "mite-biter" bee colonies and 30 bee heads from 15 Italian bee colonies. Significant differences $(p<0.05$, Student $t$ test) between Indiana "mite-biter" and Italian bee colonies were found. colonies $\left(F_{(14,26)}=8.62 ; p<0.05\right)$ and between bees of different mite-biter colonies $\left(F_{(17,33)}=\right.$ 27.19; $p<0.05$ ), evidencing high variability in gene expression between individual samples of both genotypes. A positive correlation was found between $A m N r x-1$ expression and the proportion of mutilated mites $\left(r_{s}=0.27 ; p=0.024\right.$; Supplementary Material, Figure S1). However, no significant correlation between AmNrx-1 expression and mite population growth $\left(r_{s}=-\right.$ $0.146 ; p=0.43$ ) was found.

Lastly, the proportion of colonies that survived the winter (excluding the colonies that died in September) was 0.72 for the Indiana mite-biter colonies $(N=18)$, which was three times higher than that of the Italian bee colonies $(0.27)(N=$ 15).

\section{DISCUSSION}

The aim of this study was to evaluate the Indiana mite-biter honey bee stock by comparing the phenotypes of traits used in its selection procedures (proportion of mutilated mites, severity of mutilations in mites, and $V$. destructor population growth) with those of an unselected stock of Italian commercial bees. The mite-biter colonies had a higher proportion of mutilated mites than Italian bee colonies, indicating a selection response for this trait. The mite-biting trait has been correlated with grooming behavior in previous studies (Andino and Hunt 2011). It has also been reported that colonies with high proportions of mutilated mites had lower infestation levels of $V$. destructor than colonies with low proportions of injured mites (Moosbeckhofer 1992; Mondragón et al. 2005; Guzman-Novoa et al. 2012). Nevertheless, in a previous study, Corrêa-Marques et al. (2000) did not find significant differences in the proportion of mutilated mites between presumably $V$. destructor-tolerant and susceptible colonies. The discrepancies between the studies could be related to other mechanisms of tolerance to $V$. destructor in the colonies used by CorrêaMarques et al. (2000) or to differences in methodologies. The proportion of mutilated mites in this study was relatively low compared to historical averages for the Indiana breeding population, which is about 0.45 (Hunt et al. 2016). It is 
possible that these lower rates may have been due to environmental effects, since this trait is also influenced by environmental variables (Currie and Tahmasbi 2008). Still, this study showed that the selected mite biter colonies had three times more mutilated mites compared to the unselected Italian colonies, which agrees with previous studies of $V$. destructor-resistant bee genotypes, showing higher proportions of mutilated mites than susceptible bee genotypes used as control (Rinderer et al. 2001; Guzman-Novoa et al. 2012).

In addition to the above, in this study, mites collected from the mite-biter colonies were more severely mutilated than mites collected from colonies of the unselected stock. Indiana mite-biter colonies have been selected for severity of mite mutilations and have shown higher survival rates and lower mite infestation levels than three commercial Carniolan queen sources (Hunt et al. 2016), but this is the first time that the Indiana mite-biter bees have been compared with an unselected Italian stock for this trait.

Clearly, this study shows promising results towards the aim of developing $V$. destructor tolerance in honey bees. The incorporation of selected stock in commercial operations could represent advantages to beekeepers as it would reduce the need for acaricides and potentially increase overwinter survival. The proportion of dead colonies of the selected stock $(0.28)$ in this study was still somewhat high although much lower than that of the Italian stock. It is possible that the survival of the selected stock may have been reduced by the presence of highly infested and collapsing Italian bee colonies that may have increased mite levels and disease in the nearby selected colonies. Nevertheless, the average overwintering loss of the breeding population at Purdue is much lower than the proportion of colony losses reported in the USA in 2017-2018 (0.31) (Bruckner et al. 2019), despite the fact that colonies are not treated to control $V$. destructor.

It was found that the number of fallen mites in October and $V$. destructor population growth was significantly lower in colonies from the selected stock, which could have been a consequence of differences in grooming behavior between the genotypes. Grooming behavior has been associated with restrained mite population growth (Arechavaleta-Velasco and Guzmán-Novoa 2001). Conversely, in a previous study, Moretto (2002) reported that Africanized bee colonies, presumably tolerant to $V$. destructor, showed a higher percentage of fallen dead mites than susceptible colonies. The discrepancies between the studies could be due to differences in methodologies as Moretto (2002) used colonies with only adult bees and no brood, and did not calculate $V$. destructor population growth. Thus, $V$. destructor population growth could be a more informative variable on $V$. destructor resistance than the number of fallen mites.

Variation in grooming behavior between honey bee genotypes has been previously demonstrated (Moretto et al. 1993; GuzmanNovoa et al. 2012; Rinderer et al. 2013), but it is not clear how high the heritability of this trait is, in part due to inconsistent results from different studies. Moretto et al. (1993) estimated a heritability index for grooming behavior of 0.71 , while others have reported much lower values (0.05-0.08) (Lodesani et al. 2002; Espinosa-Montaño 2006). These large differences in heritability for grooming behavior are likely due to differences in the methods used in the studies. For example, only Moretto et al. (1993) used direct observation to evaluate grooming behavior in bees. If the heritability for this trait is high (due to additive genetic effects), then it should be possible to select for increased grooming behavior in bee colonies. However, measuring grooming behavior in the field is labor-intensive and experience in visualizing mites' mutilation is required. Hence, the use of other markers (i.e., genes associated to the behavior) for selection could be of aid to assist breeding programs at a large scale.

Arechavaleta-Velasco et al. (2012) reported 27 genes in a QTL region on chromosome 5 that were linked to grooming behavior. AmNrx-1 expression was later correlated with grooming intensity in bees from a different population (Hamiduzzaman et al. 2017). In this study, the relative expression of AmNrx1 in bees from Indiana mite-biter colonies was 
significantly higher than in unselected individuals from Italian bee colonies, suggesting effects on mite-biting as part of the bees' grooming behavior. However, relative to the reference gene, AmNrx-1 expression was low, which was not unexpected as the bees used for the analysis were randomly selected from their colonies and were not bees performing selfgrooming behavior. In addition, AmNrxn-1 is only expressed in synapses of the nervous system, which may account for generally low expression levels.

$A m N r x-1$ expression was positively correlated with the proportion of mutilated mites in the selected stock but it was not significantly correlated with mite population growth. However, although the correlation was not significant, it was negative as would be expected if it does have some effect on limiting mite populations. It is possible that the high variability observed in the expression of this gene within both Italian and Indiana mite-biter colonies contributed to the non-significant correlation with mite population growth. The variation in AmNrx-1 expression could be related to the random selection of honey bees from their respective colonies. Perhaps if bees performing selfgrooming behavior had been used for the analysis the correlation could have been significant. Thus, more data is needed to test for a causal link between AmNrx-1 expression, behavior, and mite population growth. If a significant relationship is found, DNA sequence within this gene could be used as a marker to assist in selecting for tolerance to $V$. destructor in honey bee breeding programs.

This study provides evidence that selection for mite-biting behavior reduces $V$. destructor infestations, increases colony survival, and increases the expression of a grooming behavior associated gene. Further studies are warranted to confirm the validity of using $A m N r x-1$ as a potential marker to breed for resistance against $V$. destructor .

\section{ACKNOWLEDGMENTS}

The authors thank the Indiana Queen Breeders Association and the Heartland Honey Bee Breeders Cooperative for their support in providing materials for field experiments.

\section{AUTHORS' CONTRIBUTIONS}

GJH: project planning, project design, and data analysis; $\mathrm{KG}$ and $\mathrm{ME}$ : field experiments and data collection; NM and EG: molecular and statistical analyses; NM, GJH, and EG wrote the paper. All authors read and approved the final manuscript.Funding information

This study was funded by a Critical Agricultural Research and Education grant (no. 2017-6800826206/accession no. 1011721) from the USDA National Institute of Food and Agriculture.

\section{COMPLIANCE WITH ETHICAL STANDARDS}

Conflict of interest The authors declare that they have no potential conflict of interest in relation to the study in this paper.

\section{OPEN ACCESS}

This article is licensed under a Creative Commons Attribution 4.0 International License, which permits use, sharing, adaptation, distribution and reproduction in any medium or format, as long as you give appropriate credit to the original author(s) and the source, provide a link to the Creative Commons licence, and indicate if changes were made. The images or other third party material in this article are included in the article's Creative Commons licence, unless indicated otherwise in a credit line to the material. If material is not included in the article's Creative Commons licence and your intended use is not permitted by statutory regulation or exceeds the permitted use, you will need to obtain permission directly from the copyright holder. To view a copy of this licence, visit http://creativecommons.org/ licenses/by/4.0/.

Comportement de toilettage et expression génétique de la souche d'abeilles "mordeuse d'acarien" de l'Indiana.

Varroa destructor / comportement de toilettage / expression génique.

Grooming-Verhalten und Genexpression der "MilbenBeißer", eine Honigbienen-Herkunft aus Indiana. 
Varroa destructor / Grooming-Verhalten / Genexpression.

\section{REFERENCES}

Andino, G.K., Hunt, G.J. (2011). A scientific note on a new assay to measure honeybee mite-grooming behavior. Apidologie, 42 (4), 481-484.

Arechavaleta-Velasco, M., Guzmán-Novoa, E. (2001). Relative effect of four characteristics that restrain the population growth of the mite Varroa destructor in honey bee (Apis mellifera) colonies. Apidologie, 32 (2), 157-174

Arechavaleta-Velasco, M. E., Alcala-Escamilla, K., Robles-Rios, C., Tsuruda, J. M., Hunt, G. J. (2012). Fine-scale linkage mapping reveals a small set of candidate genes influencing honey bee grooming behavior in response to Varroa mites. PLoS One, 7(11), e47269. DOI: https://doi.org/10.1371/journal. pone.0047269

Bowen-Walker, P.L., Gunn, A., 2001. The effect of the ectoparasitic mite, Varroa destructor on adult worker honeybee (Apis mellifera) emergence weights, water, protein, carbohydrate, and lipid levels. Entomol. Exp. Appl. 101, 207-217.

Bruckner, S., Steinhauer, N., Aurell, S. D., Caron, D.M., Ellis, J.D., Fauvel, A.M., Kulhanek, K., McArt S.H., Mullen, E.M., Rangel, J., Sagili, R., Tsuruda, J., Wilkes, J.T., Wilson, M.E., Wyns, D., Rennich, K., vanEngelsdorp, D., Williams, G.R. (2019) Honey Bee Colony Losses 2018-2019: Preliminary Results [online] https://beeinformed.org/results/2018-2019/ (accessed July 31, 2019)

Büchler, R., Costa, C., Hatjina, F., Andonov, S., Meixner, M. D., Conte, Y. L., Drazic, M. (2014). The influence of genetic origin and its interaction with environmental effects on the survival of Apis mellifera L. colonies in Europe. J. Apic. Res. 53 (2), 205-214.

Corrêa-Marques, M. H., Issa, M. R. C., Jong, D. D. (2000). Classification and quantification of damaged Varroa jacobsoni found in the debris of honey bee colonies as criteria for selection? Am. Bee J. 140 (10), 820-824.

Currie and Tahmasbi. (2008). The ability of high and low grooming lines of honey bees to remove the parasitic mite Varroa destructor is affected by environmental conditions. Can. J. Zool. 86, 1059-1067.

Danka, R.G., Harris, J.W., Villa, J.D. (2011). Expression of Varroa sensitive hygiene (VSH) in commercial VSH honey bees (Hymenoptera: Apidae). J. Econ. Entomol. 104 (3), 745-749.

De Jong D. (1997) Mites: Varroa and other parasites of brood, in: Morse R.A. and Flottum K. (Eds.), Honey bee pests, predators, and diseases. Root Publishing, Medina, Ohio, pp. 279-327.
Delaplane, K.S., van der Steen J., Guzman-Novoa E. (2013). Standard methods for estimating strength parameters of Apis mellifera colonies. J. Apic. Res. 52 ,112.

Emsen, B., Petukhova, T., Guzman-Novoa, E. (2012). Factors limiting the growth of Varroa destructor populations in selected honey bee (Apis mellifera L.) colonies. J. Anim. Vet. Adv., 11 (24), 4519-4525.

Espinosa-Montaño, L.G. (2006) Heredabilidades y correlaciones fenotípicas para algunas características que influyen en la Resistencia de las abejas (Apis mellifera) al crecimiento poblacional del ácaro Varroa destructor en México, Ph.D. thesis, Universidad Nacional Autónoma de México.

Etherton, M. R., Blaiss, C. A., Powell, C. M., Südhof, T. C. (2009). Mouse neurexin- $1 \alpha$ deletion causes correlated electrophysiological and behavioral changes consistent with cognitive impairments. PNAS, 106 (42), 1799818003 .

Guzman-Novoa, E., Eccles, L., Calvete, Y., Mcgowan, J., Kelly, P. G., Correa-Benítez, A. (2010). Varroa destructor is the main culprit for the death and reduced populations of overwintered honey bee (Apis mellifera) colonies in Ontario, Canada. Apidologie, 41 (4), 443-450.

Guzman-Novoa, E., Emsen, B., Unger, P., EspinosaMontaño, L. G., Petukhova, T. (2012). Genotypic variability and relationships between mite infestation levels, mite damage, grooming intensity, and removal of Varroa destructor mites in selected strains of worker honey bees (Apis mellifera L.). J. Invertebr. Pathol. $110(3), 314-320$.

Hamiduzzaman, M. M., Emsen, B., Hunt, G. J., Subramanyam, S., Williams, C. E., Tsuruda, J. M., Guzman-Novoa, E. (2017). Differential gene expression associated with honey bee grooming behavior in response to Varroa Mites. Behav. Genet. 47(3), 335344.

Harbo, J.R., Harris, J.W. (2009). Responses to Varroa by honey bees with different levels of Varroa Sensitive Hygiene. J. Apic. Res. 48(3), 156-161.

Hunt, G., Given, J.K., Tsuruda, J.M., Andino, G.K. (2016). Breeding mite-biting bees to control Varroa. Bee Cult., 8, 41-47.

Ibrahim, A., Spivak, M. (2006). The relationship between hygienic behavior and suppression of mite reproduction as honey bee (Apis mellifera) mechanisms of resistance to Varroa destructor. Apidologie, 37 (1), 31-40.

Kim, H.G., Kishikawa, S., Higgins, A.W., Seong, I.S., Donovan, D.J., Shen, Y., Lally, E., Weiss, L.A., Najm, J., Kutsche, K., Descartes, M. (2008). Disruption of neurexin 1 associated with autism spectrum disorder. Am. J. Hum. Genet. 82 (1), 199-207.

Le Conte, Y., Ellis, M., Ritter, W. (2010). Varroa mites and honey bee health: can Varroa explain part of the colony losses? Apidologie, 41 (3), 353-363.

Livak, K. J., Schmittgen, T. D. (2001). Analysis of relative gene expression data using real-time quantitative PCR and the 2- $\Delta \Delta \mathrm{CT}$ method. Methods, 25 (4), 402-408. 
Lodesani, M., Crailsheim, K., Moritz, R. F. A. (2002). Effect of some characters on the population growth of mite Varroa jacobsoni in Apis mellifera L colonies and results of a bi-directional selection. J. Appl. Entomol. 126 (2-3), 130-137.

Mondragón, L., Spivak, M., Vandame, R. (2005) A multifactorial study of the resistance of Africanized and hybrid honeybee Apis mellifera to he mite Varroa destructor over one year in Mexico. Apidologie 36, 345-358

Moosbeckhofer, R. (1992) Observations on the occurrence of damaged Varroa mites in natural mite fall of Apis mellifera carnica colonies. Apidologie, 23, 523-531

Moretto, G. (2002). Mortality of Varroa destructor in broodless Africanized and Carnica honey bee (Apis mellifera L.) colonies. Interciencia, 27 (12), 702-704.

Moretto, G., Gonçalves, L. S., De Jong, D. (1993). Heritability of Africanized and European honey bee defensive behavior against the mite Varroa jacobsoni. Rev. Bras. Genet. 16, 71-71

Morfin, N., Goodwin, P.H., Hunt, G.J., Guzman-Novoa, E. (2019). Effects of sublethal doses of clothianidin and/ or $V$. destructor on honey bee (Apis mellifera) selfgrooming behavior and associated gene expression. Sci. Rep. 9, 5196

R Core Team (2014). R: A language and environment for statistical computing. R Foundation for Statistical Computing. Vienna, Austria. http://www.R-project. org/.

Reyes-Quintana, M., Espinoza-Montaño, L.G., PrietoMerlos, D., Koleoglu, G., Petukhova, T., CorreaBenítez, A., Guzman-Novoa, E. (2019). Impact of
Varroa destructor and deformed wing virus on emergence, cellular immunity, wing integrity and survivorship of Africanized honey bees in Mexico. J. Invertebr. Pathol. 164, 43-48.

Rinderer, T.E., de Guzman, L.I., Delatte, G.T., Stelzer, J.A., Lancaster, V.A., Kuznetsov, V., Beaman, L., Watts, R., Harris, J.W. (2001). Resistance to the parasitic mite Varroa destructor in honey bees from far-eastern Russia. Apidologie, 32 (4), 381-394.

Rinderer, T. E., Harris, J. W., Hunt, G. J., De Guzman, L. I. (2010). Breeding for resistance to Varroa destructor in North America. Apidologie, 41 (3), 409-424.

Rinderer, T. E., De Guzman, L. I., Frake, A. M. (2013). Associations of parameters related to the fall of Varroa destructor (Mesostigmata: Varroidae) in Russian and Italian honey bee (Hymenoptera: Apidae) colonies. J. Econ. Entomol. $106(2)$, 566-575.

Tabuchi, K., Südhof, T.C. (2002). Structure and evolution of neurexin genes: insight into the mechanism of alternative splicing. Genomics, 79 (6), 849-859.

Thompson, G.J., Yockey, H., Lim, J., Oldroyd, B.P. (2007). Experimental manipulation of ovary activation and gene expression in honey bee (Apis mellifera) queens and workers: testing hypotheses of reproductive regulation. J. Exp. Zool. A Ecol. Genet. Physiol. 307 (10), 600-610.

Publisher's note Springer Nature remains neutral with regard to jurisdictional claims in published maps and institutional affiliations. 